\title{
ROMANIAN
}

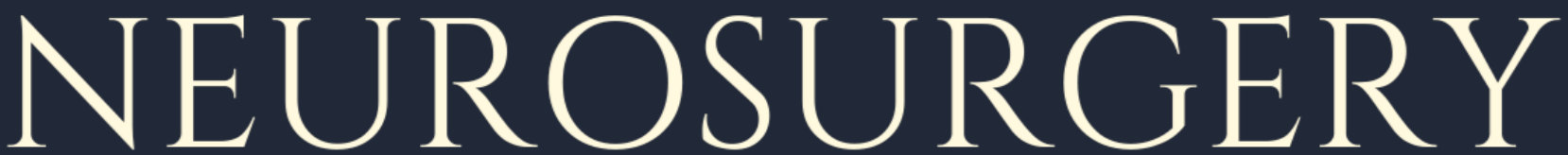

\author{
Vol. XXXIV | No. $1 \quad$ March 2020
}

\section{A giant occipital encephalocele. A case report}

M. Al-Zekri, F. Aichaoui, A. Khelifa, A. Morsli 


\title{
A giant occipital encephalocele. A case report
}

\author{
M. Al-Zekri, F. Aichaoui, A. Khelifa, A. Morsli \\ Department of Neurosurgery, CHU Bab El Oued, Algiers, ALGERIA
}

\begin{abstract}
Occipital encephalocele is a rare congenital anomaly that is characterized by herniation of brain tissue through a defect in the skull. Because of their enormous size, they pose a surgical challenge. Occipital encephalocele is the commonest of all encephalocele; the management of encephalocele defects requires immediate surgical closure. The author reports a case of a five months old female baby who presented a progressively increasing swelling over the occipital region. This swelling was present since birth. Surgery was planned to reduce the size of the swelling as well as its contents. The sac was excised and reduced sufficiently enough to accommodate the healthy-looking brain tissue. This infant did well postoperatively.
\end{abstract}

\section{INTRODUCTION}

An encephalocele is a congenital herniation of intracranial contents throughout a cranial defect. The intracranial contents which extrude to the exterior from the defect, may incorporate cerebrospinal fluid (CSF), meningeal structures, or/and brain tissue $(2,4)$. Occipital encephaloceles constitute 80 to $90 \%$ of all encephaloceles and occurs between the lambda and the foramen magnum, predominantly in the midline $(1,4,5)$. In giant occipital encephaloceles the size of the swelling is larger than the size of the head from which they arise, and because of their enormous size they pose a surgical challenge $(1,3,5)$. Meningoencephalocele is diagnosed antenatally using sonography; it can achieve diagnostic accuracy in $80 \%$ of cases. Other imaging modalities including: CT scan, MRI (6) and the management of encephalocele defects requires immediate surgical closure (5).

\section{CASE PRESENTATION}

A five months female baby presented with progressively increasing swelling over the occipital region since birth. The baby was born at term from consanguineous marriage. On neurological examination the patient was conscious; in a general state preserved with a weight of 7 kg. She has a slight psychomotor delay with a closed anterior fontanel. Local examination showed: an occipital encephalocele of large size, well epidermised, measuring $28 \mathrm{~cm}$ with relatively wide neck (Fig.1).

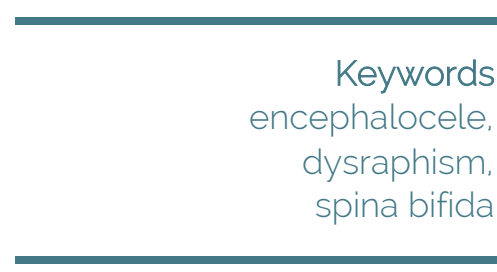

$\triangle$

Corresponding author: Muneer Al-Zekri

Department of Neurosurgery, $\mathrm{CHU}$ Bab El Oued, Algiers, Algeria

muneeralzekri3o@yahoo.com

Copyright and usage. This is an Open Access article distributed under the terms of the Creative Commons Attribution Non-Commercial No Commons Attribution Non-Commercial No
Derivatives License (https://creativecommons Derivatives License (https://creativecommons
org/licenses/by-nc-nd/4.0/) which permits noncommercial re-use, distribution, and reproduction in any medium, provided the original work is unaltered and is properly cited.

The written permission of the Romanian Society of Neurosurgery must be obtained for commercial re-use or in order to create a derivative work.

ISSN online 2344-4959 (C) Romanian Society of Neurosurgery

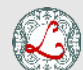

First published March 2020 by -ondon Academic Publishing www.lapub.co.uk 
Magnetic Resonance Imaging (MRI) of the brain showed a giant encephalocele at the occipital region with cerebral hernia and meninges across a large bone defect (Fig.2 A, B). Surgical treatment consists of the exclusion of the malformation while respecting the healthy brain tissue. The patient was put in lateral position; first, we reduced the volume of the sac by subtracting its cerebrospinal fluid (LCS) content; then, a circumferential incision was placed over the sac, and the neck was dissected out; after that, the sac was opened to expose nervous content. The resection of the sac and non-functional cerebral tissue was performed up to the limit of the healthy tissue visible next to the bone defect. in the end a watertight meningeal closure was done, with cutaneous and subcutaneous closure (Fig. 3 $A, B, C, D, E, F)$. The post-operative course was without complications.

Figure 1. Preoperative picture showing massive occipital encephalocele.

Figure 2. Preoperative T1 WI MRI; A: Sagittal, and B: transversal.

Figure 3. Preoperative views; A: LCS extraction, B: incision over the sac, C: Sac was then opened and exposure of its nervous content, D: resection of the sac, E: meningeal closure, $F$ : cutaneous and subcutaneous closure.
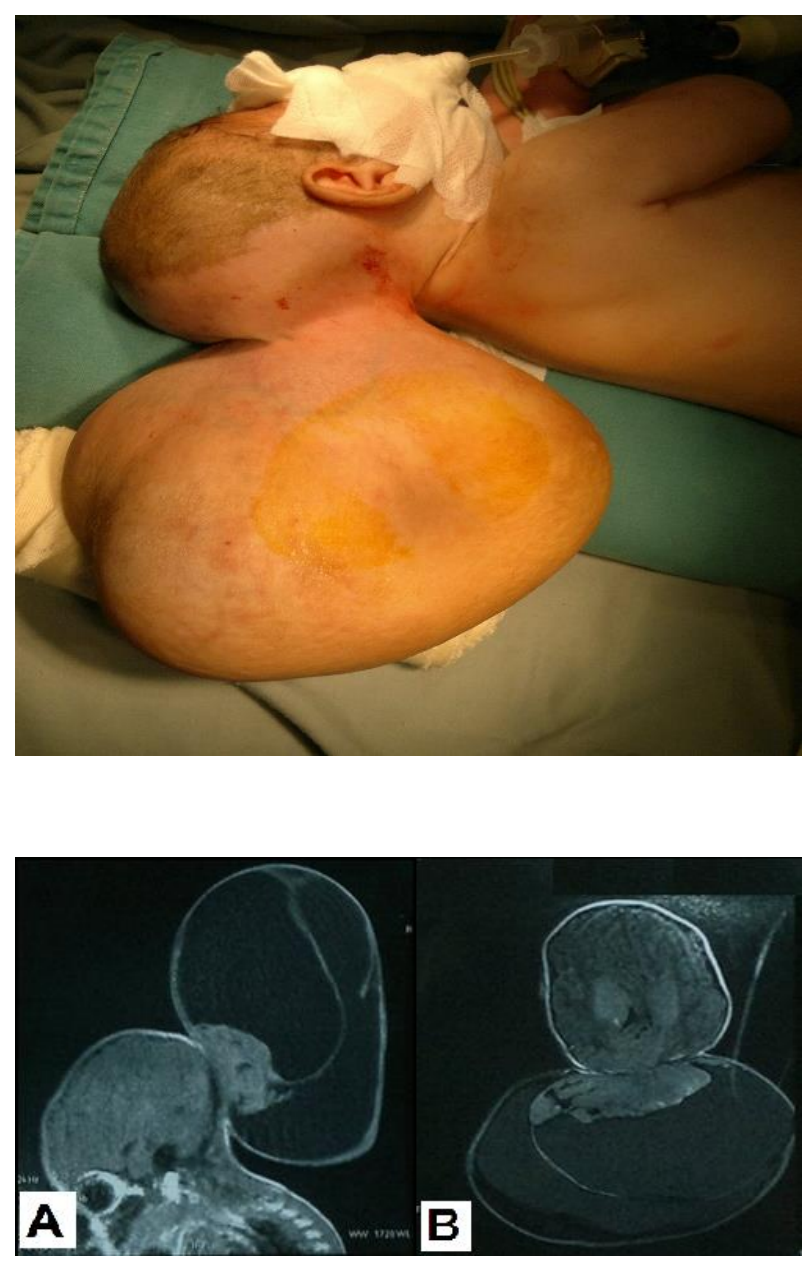
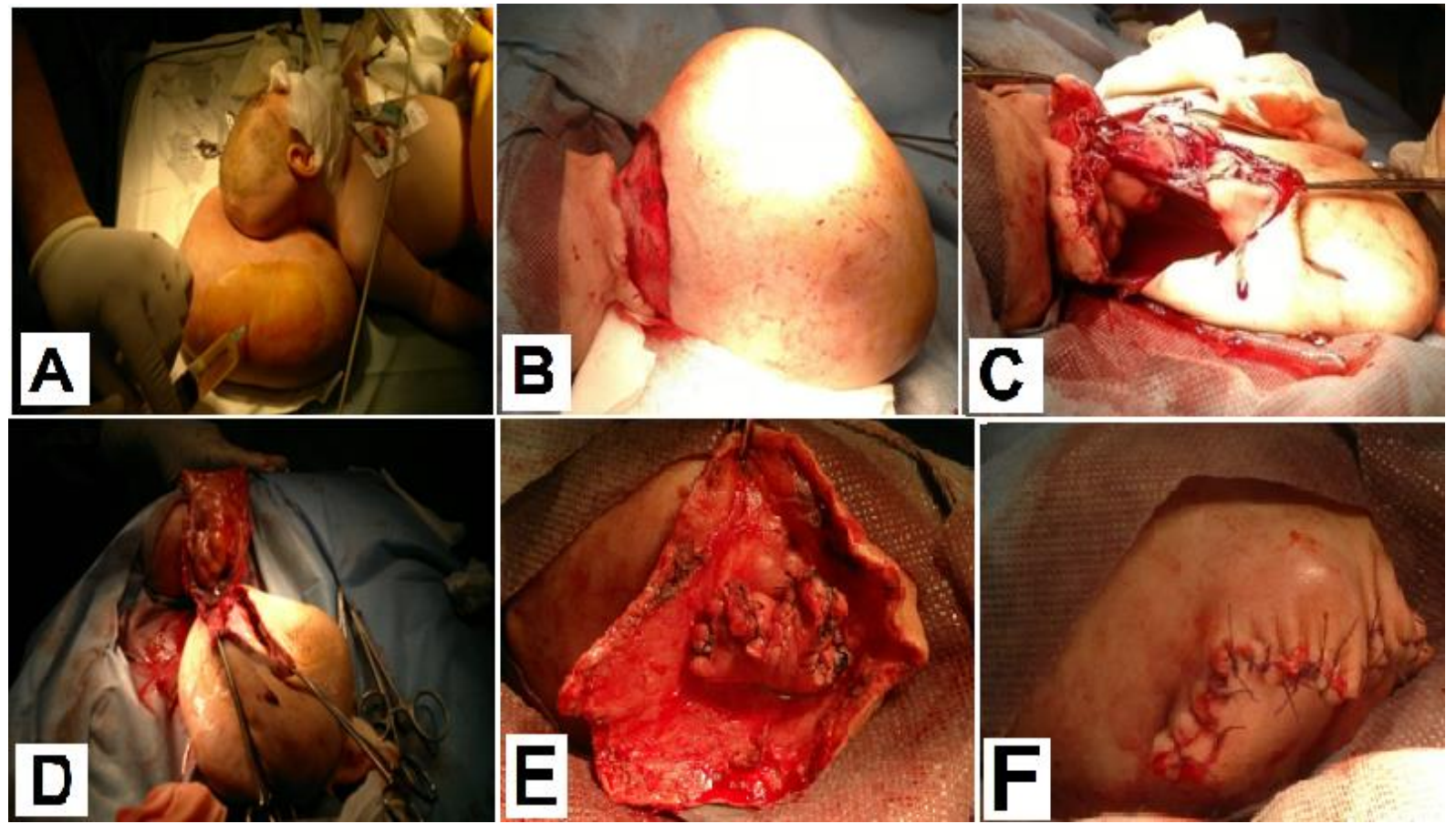


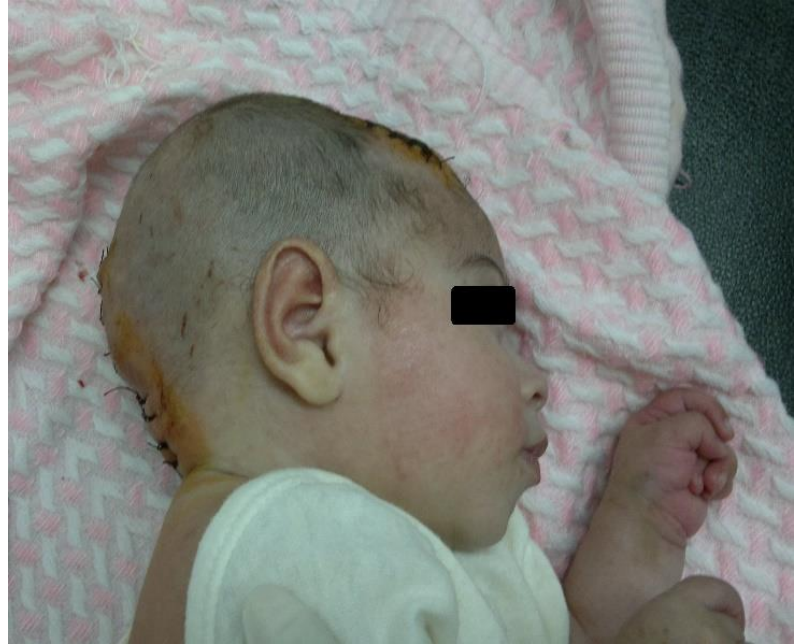

Figure 4. Postoperative picture.

\section{DISCUSSION}

Encephaloceles are congenital anomalies of the central nervous system. They are protrusions of brain tissue. The cranial defect lead to the development of a sac with variable contents $(2,4,7)$. The content of occipital encephalocele may include meninges, occipital lobes, or ventricles and rarely contain cerebellum, brainstem, or torcula. Typically, bony defect may be only confined to only occipital bone or may descend down to involve defect of the posterior lip of foramen magnum and even up to the posterior arch of the atlas and accordingly divided into supra and infra torcular types $(4,5)$. The size of occipital encephalocele may vary from small, large to giant and could be pedunculated or sessile (1). It may be associated with hydrocephalus; or other organs and extremities malformations. Cortical dysplasia and corpus callosum agenesis are frequently present $(4,5)$. Encephaloceles account for 10 to $20 \%$ of all craniospinal dysraphisms and $80 \%$ of them are occipital. They are more common in female than male $(1,3,5)$. Encephalocele is believed to be multifactorial: genetic and environmental. Genetic background may increase the risk of developing this condition. Also, due to close relationship between encephalocele and neural tube defects, folate deficiency has been believed to play a role in the pathogenesis of encephalocele (6). These lesions are usually covered either with normal skin, dysplastic skin or a thin distorted meningeal membrane (3). The severity of mental retardation is higher and the prognosis is worse in cases neural aberrations asssociation. In a study supported by French et al.
$17 \%$ of patients with encephaloceles had normal development, whereas severe mental retardation and physical delay were present in $83 \%$ of the patients (4). MRI could reveal the exact anatomical description of the encephalocele and displaced brain structures; it also reveals the configuration of the brainstem regions. Moreover, postnatal follow-up MRI confirms the prenatal findings and shows additional morphological information such as vascular anatomy. Furthermore, Magnetic Resonance Angiography is the optimal investigation to visualize the relationship of the sac to the venous sinuses; while CT scans are used to detect the extent of cranial defect (6). Patients with a large encephalocele are considered complicated cases because of CSF leakage or difficulty in repositioning the viable extruded brain tissue inside the cranium without increasing intracranial pressure (4). Further, torcula as a content poses a great challenge as its injury may lead to cerebral deep venous system thrombosis (5). Surgery is indicated for esthetic goal, to avert the risk of rupture, CSF leak, and meningitis. Before incision, aspiration of CSF may aid in the dissection of the sac, especially in large or giant encephalocele (5). The surgical intervention involves excision of the nonfunctional neural tissues hernia with dural repair. In case of a very large cerebral hernia, surgical treatment may be limited only to wide cranioplasty. Intra-operatively, care must be taken to identify the contents of the sac. Rarely, the sagittal sinus, torcula and transverse sinus are in the vicinity of the sac. Major veins should be spared to prevent any venous infarction (8). In the postoperative period, the possibility of aggravation of hydrocephalus should be kept in mind and its occurring may need shunt surgery; about $60 \%$ of posterior encephalocele may develop hydrocephalus requiring surgical management (5). The factors of poor prognosis are microcephaly with neurological disorder and the importance of the nervous elements inside the sac including the brain, the cerebellum and the brainstem.

\section{CONCLUSION}

Encephaloceles are rare and complicated defects. It is associated with other congenital anomalies such as hydrocephalus, Dandy-Walker malformation, and microcephaly. Its treatment like excision and repair when done in early age, greatly reduces 
complications like CSF leak, reduced IQ level of the patients and other effects of associated anomalies are controlled in time. Closed monitoring postoperatively is essential as the patient may developed hydrocephalus and required ventriculo-peritoneal shunt.

\section{REFERENCES}

1. H. D. Nath, A. K. Mahapatra, S. A. Borkar: A giant occipital encephalocele with spontaneous hemorrhage into the sac: A rare case Asian Journal of Neurosurgery Vol. 9, Issue 3, July-September 2014 DOI:10.4103/17935482.142736.

2. Lal Rehman, Ghulam Farooq, Irum Bukhari: Neurosurgical interventions for occipital encephalocele, Rehman L, Farooq G, Bukhari I. Neurosurgical interventions for occipital encephalocele. Asian J Neurosurg 2018; 13:233-7.

3. Amit Agarwal, Aruna Vijay Chandak, Anand Kakani, Shivshankar Reddy: A giant occipital encephalocele
Agarwal A, Chandak AV, Kakani A, Reddy S. A giant occipital encephalocele. APSP J Case Rep 2010; 1:16

4. Ashraf El Badrya ,Azza Abdel Azeez, Ahmed AbdelKhalek: Microsurgical management results of occipital Benha Medical Journal, Vol. 35 No. 2, May-August 2018

5. Guru Dutta Satyarthee, Luis Rafael Moscote-Salazar, Nidia Escobar Hernandez, Jose Aquino-Matus, Paulo Cesar Puac-Polanco, Samer S Hoz, Willem Guillermo Calderon-Miranda: A giant occipital encephalocele in neonate with spontaneous hemorrhage into the encephalocele sac: Surgical management. J Pediatr Neurosci 2017; 12:268-70.

6. Ahmed Alwahab, Adnan Kharsa, Alaa Nugud and Shomous Nugud: Occipital meningoencephalocele case report and review of current literature Alwahab et al Chinese Neurosurgical Journal (2017) 3:40, DOI 10.1186/s41016-017-0104-5.

7. Ashfaq UI Hassan : A giant occipital encephalocele Universal Journal of Applied Science 1(1): 8-10, 2013

8. Sim SK, Theophilus SC, Noor Azman AR :Surgical management of large occipital encephalocoele: A Case Report the International Medical Journal Malaysia Volume 13 Number 2, Dec 2014. 